\title{
CHANGES IN SOIL WATER CONTENT WITH AMBIENT RELATIVE HUMIDITY IN RELATION TO THE ORGANIC MATTER AND CLAY
}

\author{
DAL Leelamanie \\ Department of Soil Science, Faculty of Agriculture, University of Ruhuna, Mapalana, Kamburupitiya, \\ Sri Lanka.
}

Accepted: $11^{\text {th }}$ February 2010

\begin{abstract}
Changes in soil water content with increasing ambient relative humidity was examined using model soils prepared by mixing silica sand with different types of organic matter and different types and contents of clays. In this study, we used commercially available hydrophobic and hydrophilic organic matter, and kaolinite and montmorillonite under four levels of relative humidities. Soil water content of all the soils increased with increasing relative humidity. Hydrophilic organic matter, which is reported to decrease the wettability of soils, was found to increase the absorption of water into soils in the vapor form. In model soils without clay, hydrophobic organic matter, which is reported to impede water entry in liquid form (water repellent), was found to have little or no effect on water vapor absorption. In contrast, when the model soils containing 1-2\% clays, hydrophobic organic matter slightly decreased the water vapor absorption. Montmorillonite containing samples showed higher water vapor absorption, and therefore, higher water contents compared with those containing kaolinite. The difference in water content between samples containing montmorillonite and kaolinite increased with increasing clay content. Increase in clays with high water absorption capacity was found to make the clay effects on water vapor absorption prominent and to hinder the effects of hydrophobic or hydrophilic organic matter on water vapor absorption. The absorption of water into soils in vapor form was found not to be comparable with previously reported wetting of soils with water, in liquid form.
\end{abstract}

Key words: clay, organic matter, water repellency, water vapor absorption, wettability

\section{INTRODUCTION}

Soil water content is a very important soil property which related with many other important soil properties and processes. In fact, the water content in the soil surface is very important for many soil physical properties and phenomena, especially the infiltration, wettability, and aggregate stability. Ambient relative humidity $(\mathrm{RH})$ or the water potential is one of the most important factors that affect the water content and the wettability in surface soil (Doerr et al. 2002; Goebel et al. 2004). Water content in the surface soil changes with increasing or decreasing environmental water potential and is dependent on the properties and the basic components of soils such as types and contents of organic matter and clays present in the soil.

Soil organic matter consists of main two types that are identified as hydrophobic and hydrophilic (Ellerbrock et al. 2005). Hydrophobic organic matter has been identified to cause extreme water repellency in soils (Doerr et al., 2005; Franco et al. 2000; Leelamanie and Karube 2007). Water repellency retards the spontaneous wetting of soils when water is applied on the surface. Water repellency in soils will primarily affect the infiltration rates.

Hydrophilic organic matter, though it is called hy- drophilic, is also reported to increase the soil-water contact angle, which is a measure of the magnitude of the water repellency. Therefore, hydrophilic organic matter is also considered to decrease the wettability of soils, the ability of soils to absorb liquid water into the surface. This can be attributed the surface free energy of organic matter, which is always lower compared with that of mineral soils. The higher the surface free energy, the higher the wettability. However, compared with hydrophobic organic matter hydrophilic organic matter only slightly reduces the wettability (Leelamanie and Karube 2009).

Although both hydrophobic and hydrophilic organic matter are reported to decrease the wettability of soils, their effect on water vapor absorption into the surface soils has not been tested so far. Types and contents of clays present in soils is another factor that affects the wettability of soils. Clays are reported to decrease the extreme water repellency (penetration time of water drop $>1 \mathrm{~h}$ ) in soils (McKissock et al. 2000, 2002; Leelamanie et al. 2010), which might be a result of their high surface free energy. On the contrary, clays may decrease the wettability in wettable or non repellent soils (Leelamanie and Karube 2007; Leelamanie et al. 2010). However, information on the water vapor absorption into surface soils with different types

*Corresponding author : leelamanie@soil.ruh.ac.lk,leelamaniee@yahoo.co.uk 
and contents of clays, especially in combination with different types of organic matter is not available.

It would be important to clarify the combined effects of organic matter and clay on the water vapor absorption because the combined effects of these components on soil wettability (liquid water absorption into the surface) are reported to be incomparable with their individual effects (Leelamanie and Karube 2007).

Experimental observations are lacking for the effects organic matter and clays, which are reported to be important factors affecting wettability of soils, on water vapor absorption into surface soils with the changes in ambient RH. The objective of this study was to examine the effects of hydrophobic and hydrophilic organic matter and different types and contents of clays on water vapor absorption into the soil under four levels of ambient RHs using model soils prepared by mixing silica sand with commercially available pure chemicals.

\section{MATERIALS AND METHODS}

\section{Materials}

Fine silica sand with particle diameter of $94 \%$ of mass ranging from 45 to $150 \mathrm{~mm}$ was used as the base material to prepare the model soils. Stearic acid (molecular weight: 284.5) and konjac-derived glucomannan (Wako pure chemical industries, Osaka, Japan) were used as hydrophobic and hydrophilic organic compounds, respectively. Georgian kaolinite and Wyoming Na-montmorillonite (The Clay Minerals Society, USA) were used as clays.

Stearic acid was chosen because it can be considered as a common organic acid in natural soil (Deng and Dixon, 2002). Glucomannan was chosen because it is a neutral polysaccharide gum, as positive or negative charges might have an effect on wetting properties.

\section{Sample preparation}

To prepare the model soils containing hydrophobic organic compound, the sand was mixed with $1 \mathrm{~g} \mathrm{~kg}$

${ }^{-1}$ stearic acid, because the total lipid content in natural soil is considered to be about $1 \mathrm{~g} \mathrm{~kg}^{-}{ }^{1}$ (Martens et al. 2003). Since stearic acid is insoluble in water, it was dissolved in diethyl ether to make a solution with hydrophobic organic compound. Then the solution was added to the sand in glass containers in a fume hood. The containers were sealed immediately because the diethyl ether is a highly volatile. The sand was thoroughly mixed with the stearic acid solution in the sealed container and then placed in open porcelain containers. In general, volatilization of diethyl ether takes about 30 minutes. The samples were left for $2 \mathrm{~h}$ in the hood to allow complete volatilization of diethyl ether to avoid unnecessary effects if any and kept for one day.

The sand was mixed with $10 \mathrm{gkg}-{ }^{1}$ glucomannan to prepare the model soils containing hydrophilic organic compound. Glucomannan was dissolved in deionized water to prepare a suspension with hydrophilic organic matter. This suspension was then thoroughly mixed with the sand using a spatula. The samples were dried at $30^{\circ} \mathrm{C}$ for one day. To prepare the model soils containing both hydrophobic and hydrophilic organic compounds, sand was first mixed with stearic acid, kept for one day, and next mixed with glucomannan as described above.

Air dried samples were placed in glass vials and air dried kaolinite or Na-montmorillonite was added to the model soils to obtain 1,2 , and $5 \%$ of clay contents. The vials were thoroughly shaken for 2 minutes to mix the clay with the model soils.

Model soils with $0,0.5,1.0,3.0,5.0$, and $10.0 \mathrm{~g} \mathrm{~kg}^{-1}$ stearic acid were prepared to find the effect of different stearic acid contents on water vapor absorption to the surface soils.

\section{Exposure to relative humidity}

About $5 \mathrm{~g}$ of each sample in three replicates were used for the measurements. Samples in weighing bottles with 12-mL volume were exposed to $\mathrm{RH}$ levels of $33,57,75$, and $94 \%$ in a constant temperature room at $25^{\circ} \mathrm{C}$ for 20 to $22 \mathrm{~h}$. The RH levels of $33,57,75$, and $94 \%$ were obtained using saturated salt solutions of $\mathrm{MgCl} 2 \cdot 6 \mathrm{H} 2 \mathrm{O}, \mathrm{NaBr}, \mathrm{NaCl}$, and KNO3, respectively (The Japan Society for Analytical Chemistry 2004), in sealed glass chambers. The exposure time was determined based on a water retention experiment in which hydrophobized sand was first equilibrated at $30 \%$ and then exposed to $75 \% \mathrm{RH}$. The equilibrium condition was observed to be achieved within $24 \mathrm{~h}$. During the measurements, the $\mathrm{RH}$ of the constant temperature room was kept close to the respective RH in the chamber using a humidifier and a dehumidifier. During the experiments with $33,57,75$ and $94 \%$ RHs, the RH of the constant temperature room was 30-32, 56$59,72-75$ and $90-95 \%$, respectively. Water contents of the samples at each RH were measured mass metrically.

Results are expressed in terms of mean \pm standard deviation.

\section{RESULTS AND DISCUSSION}

Results of this study showed that the water content of all the model soils increased with increasing ambient RH.

Increase in water content with increasing RH when the soils were not treated with clay is presented in Figure 1. Water content of glucomannan containing soils gradually increased with increasing RH. In 
soils without glucomannan, the increase in water content was slight up to $75 \% \mathrm{RH}$. The water content of both glucomannan containing soils was high compared with that of soils without glucomannan. The water contents of samples without organic matter (sand only) and those with hydrophobic stearic acid were found to be comparable. The figure shows that the presence of stearic acid did not affect the water content of the samples free of clay. Water content of model soils with $0,0.5,1.0,3.0$, 5.0 , and $10.0 \mathrm{gkg}_{-}{ }^{1}$ stearic acid contents, where the repellency was found to be in a range of nonrepellent to extremely repellent, is presented in Figure 2 . The figure clearly shows that the increase in hydrophobic stearic acid content did not affect the water absorption in vapor form into model soils at different RHs. Miyamoto et al. (1972) observed no specific relationship between water vapor adsorption and water repellency using soils with contact angles below $90^{\circ}$. The present results were agreed with Miyamoto et al. (1972) in the absence of clay. Adamson (1968) explained that the adsorbed water layer have a relationship with contact angle of plane surfaces, at $\mathrm{RH}$ higher than $80 \%$ and, presumably contact angles below $90^{\circ}$. This principle, though it might be applicable for idealistic conditions as explained by Adamson (1968), seemed inappropriate for water absorption into soils in vapor form as presented in Figure 1 and 2.

Water contents of samples containing 1, 2, and 5\% clay (kaolinite and montmorillonite) with increasing $\mathrm{RH}$ are respectively given in Figures 3, 4, and 5 .

According to the Figures 1, 3, 4, and 5 the samples containing glucomannan showed higher water contents compared with the other samples, irrespective of the presence of hydrophobic stearic acid.

Organic matter, whether hydrophobic or hydrophilic, are reported to increase the soil-water con-

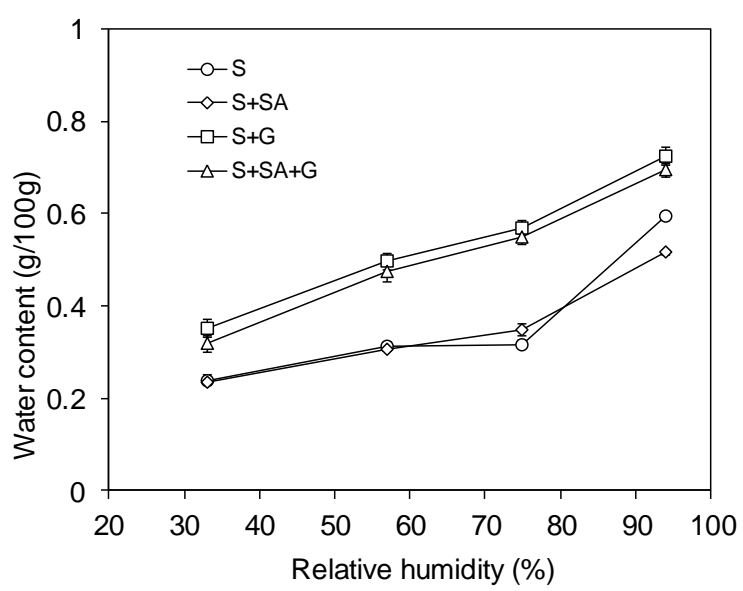

Figure 1 Water content at different relative humidities in samples with $0 \%$ clay. $S$, sand; SA, stearic acid; G, glucomannan. Error bars indicate \pm S.D. tact angle (decrease the wettability of soils, that is, impede the liquid water entry into the soil). Though hydrophobic organic matter increases the contact angle in a greater degree, hydrophilic organic matter only slightly increases the contact angle (Leelamanie and Karube 2009). These slight increases in contact angle, although it may not cause apparent or extreme hydrophobicity, may affect the hydrological processes of soils such as the infiltration rate (Wallis et al. 1991).

Accordingly, the ability of hydrophilic organic matter to decrease wetting of soils by liquid water can be considered inapplicable for water vapor absorption by soils containing hydrophilic organic matter, irrespective of the presence of clay.

As presented in Figures 3 and 4, presence of $1-2 \%$ clay was found to create a difference in water content between samples with and without stearic acid. The samples containing stearic acid showed slightly lower water contents compared with those free of stearic acid. This effect was obvious in the presence of both stearic acid and glucomannan. This suggests that the presence of small amount of clay and hydrophilic organic matter induces the hydrophobic nature of stearic acid to repel water vapors as well. Figures 3, 4, and 5 showed that both the type and the content of clay affected the water vapor absorption capacity of the model soils. Water content of samples increased with increasing $\mathrm{RH}$ irrespective of the type of clay. However, the increase in water content was more obvious in samples containing montmorillonite.

Water content of samples increased with increasing clay content. The increase in water content was more obvious in those containing montmorillonite. In samples with $1 \%$ clay (Fig. 3), montmorillonite containing samples showed slightly higher water contents compared with those containing kaolinite. This can be considered as a result of the higher wa-

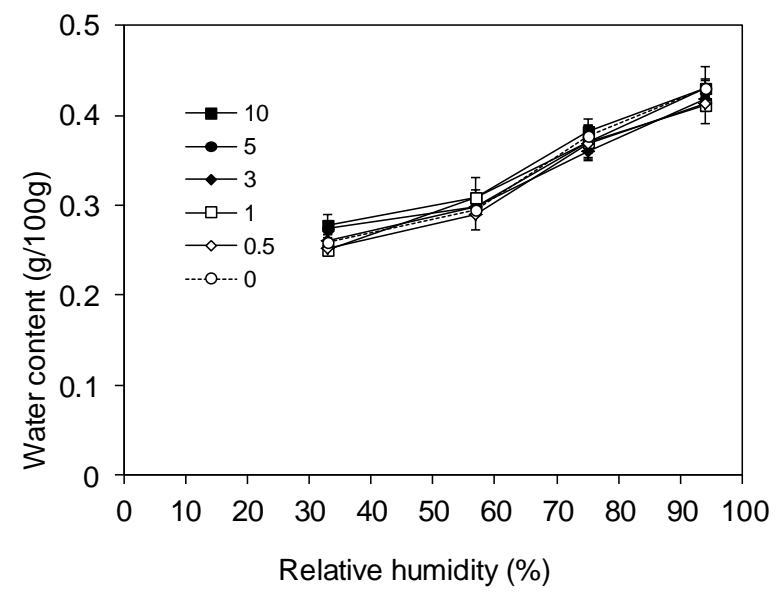

Figure 2 Water content at different relative humidities in samples with $0,0.5,1.0,3.0,5.0$, and 10.0 stearic acid. Error bars indicate \pm S.D. 


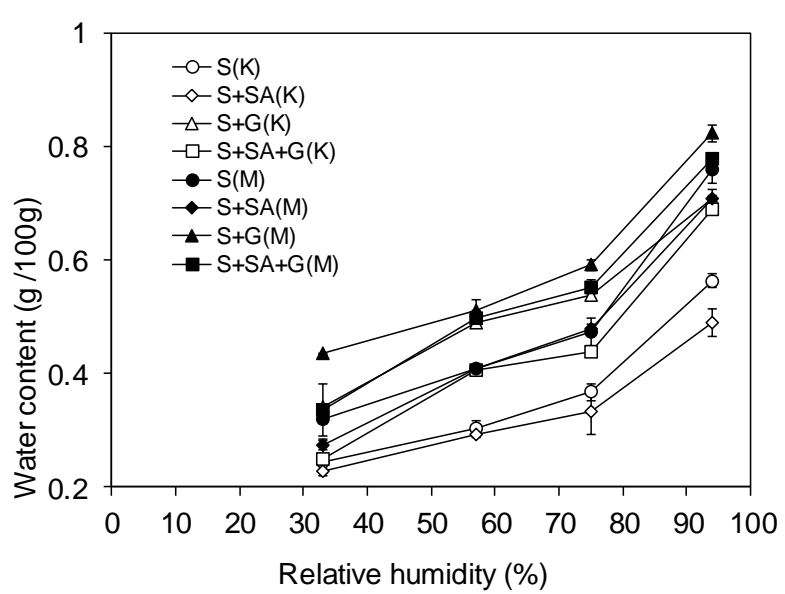

Figure 3 Water content at different relative humidities in samples with $1 \%$ clay. $S$, sand; $S A$, stearic acid; G, glucomannan; K, kaolinite; M, montmorillonite. Error bars indicate \pm S.D.

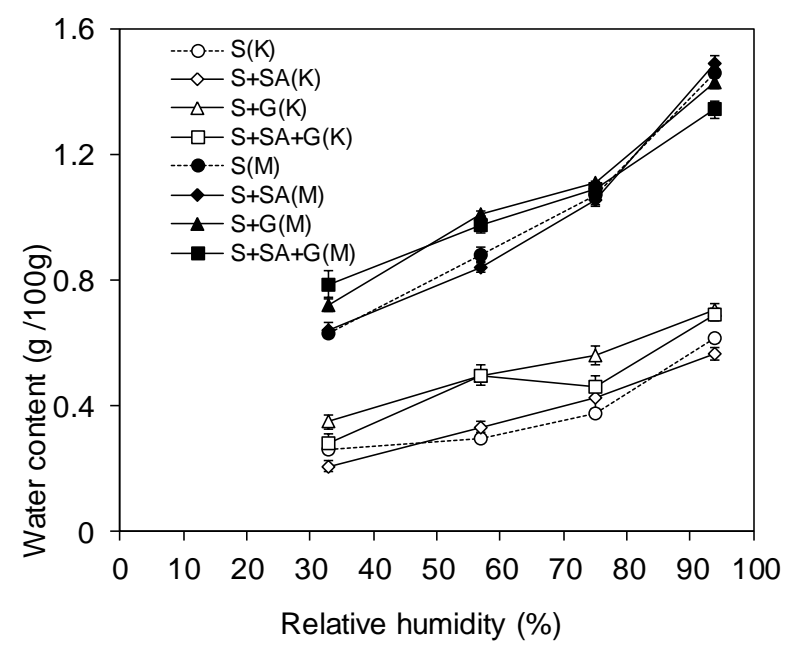

Figure 5 Water content at different relative humidities in samples with $3 \%$ clay. S, sand; SA, stearic acid; G, glucomannan; K, kaolinite; $M$, montmorillonite. Error bars indicate \pm S.D.

ter absorption capacity of montmorillonite compared with that of kaolinite. The difference in water content between samples containing montmorillonite and kaolinite increased with increasing clay content as presented in Figures 4 and 5.

In samples with 2 and $5 \%$ clay (Figure 4,5 ), all the samples containing montmorillonite showed higher water contents compared with those containing kaolinite. In samples with 5\% clay (Figure 5), the difference in water content between samples containing kaolinite and montmorillonite was highly obvious. All the samples containing montmorillonite showed considerably higher water content than those containing kaolinite.

In the samples containing 5\% montmorillonite, the effect of hydrophobic or hydrophilic organic matter on water vapor absorption was not clear. However,

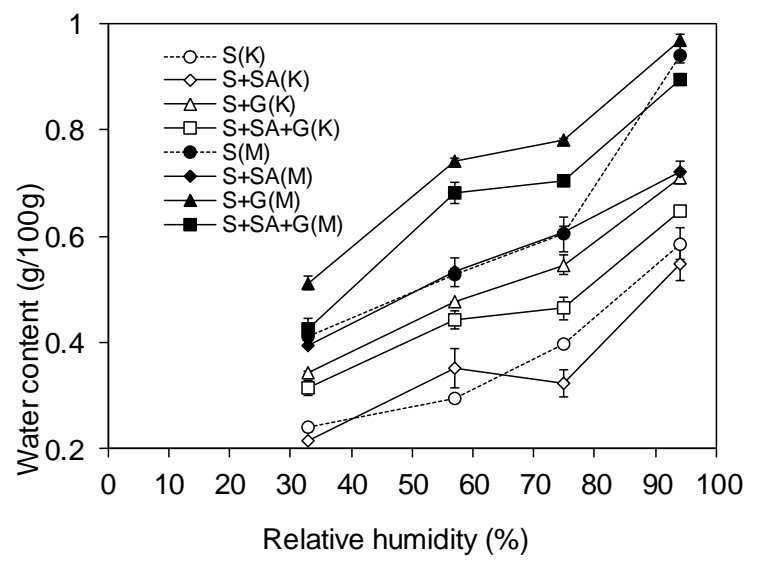

Figure 4 Water content at different relative humidities in samples with $2 \%$ clay. S, sand; SA, stearic acid; G, glucomannan; K, kaolinite; $M$, montmorillonite. Error bars indicate \pm S.D.

in samples containing 5\% kaolinite, glucomannan containing samples showed slightly higher water content compared with other samples. This suggests that the increase in clays with high capacity for water absorption, such as montmorillonite, can suppress the effects of hydrophobic or hydrophilic organic matter on water vapor absorption. The results of this study revealed that the absorption of water into soils in vapor form was not comparable with the previously reported findings on wetting of soils with water, in liquid form

\section{CONCLUSIONS}

Hydrophilic organic matter, which is reported to decrease the wettability of soils, was found to increase the water absorption into soils in vapor form. Hydrophobic organic matter, which is reported to impede water entry to soils in great degrees, was found to have little or no effect on water vapor absorption into the soils in the absence of clay. In contrast, when the model soils were containing small amounts of clays, hydrophobic organic matter slightly decreased the water vapor absorption.

Montmorillonite containing samples showed higher water contents compared with those containing kaolinite, which can be considered as a result of the higher water absorption capacity of montmorillonite compared with that of kaolinite. The difference in water content between samples containing montmorillonite and kaolinite increased with increasing clay content.

Increase in clays with high capacity for water absorption was found to make the clay effects on water vapor absorption prominent and to hinder the effects of hydrophobic or hydrophilic organic matter on water vapor absorption.

Absorption of water into soils in vapor form was found not to be comparable with previously 
reported wetting of soils with water, in liquid form.

\section{ACKNOWLEDGEMENT}

I express my sincere gratitude to Prof. Jutaro Karube, Faculty of Agriculture, Ibaraki University, Japan, for his kind corporation in providing laboratory facilities, including chemicals.

\section{REFERENCES}

Adamson AW 1968 An adsorption model for contact angle and spreading. J. Colloid Interface Sci., 27: 180-187.

Deng Y and Dixon JB 2002 Soil organic matter and organic-mineral interactions. pp. 69-107. In: JB Dixon and DG Schulze (ed.) Soil Mineralogy with Environmental Applications. SSSA Book Ser. No. 7. SSSA, Madison, WI, USA.

Doerr SH, Dekker LW, Ritsema CJ, Shakesby RA and Bryant R 2002 Water repellency of soils: The influence of ambient relative humidity. Soil Sci. Soc. Am. J., 66: 401- 405.

Doerr SH, Llewellyn CT, Douglas P, Morley CP, Mainwaring KA, Haskins C, Johnsey L, Ritsema CJ, Stagnitti F, Allinson G, Ferreira AJD, Keizer JJ, Ziogas AK and Diamantisf J 2005 Extraction of compounds associated with water repellency in sandy soils of different origin. Aust. J. Soil Res., 43: 225-237.

Ellerbrock RH, Gerke HH, Bachmann J and Goebel M-O 2005 Composition of organic matter fractions for explaining wettability of three forest soils. Soil Sci. Soc. Am. J., 69: 57-66.

Franco CMM, Clarke PJ, Tate ME and Oades JM 2000 Hydrophobic properties and chemical characterization of natural water repellent materials in Australian sands. J. Hydrol., 231-232: 47 -58 .

Goebel M-O, Bachmann J, Woche SK, Fischer WR and Horton R 2004 Water potential and aggregate size effects on contact angle and surface energy. Soil Sci. Soc. Am. J., 68: 383-393.
Leelamanie DAL and Karube J 2007 Effects of organic compounds, water content and clay on the water repellency of a model sandy soil. Soil Sci. Plant Nutr., 53: 711-719.

Leelamanie DAL, Karube J and Yoshida A 2008 Relative humidity effects on contact angle and water drop penetration time of hydrophobized fine sand. Soil Sci. Plant Nutr., 54: 695-700.

Leelamanie DAL and Karube J 2009 Effects of hydrophobic and hydrophilic organic matter on the water repellency of model sandy soils Soil Sci. Plant Nutr., 55: 462-467.

Leelamanie DAL, Karube J and Yoshida A 2010 Clay effects on contact angle and water drop penetration time of model soils. Soil Sci. Plant Nutr., 56: 371-375.

Martens DA, Reedy TE and Lewis DT 2003 Soil organic carbon content and composition of 130 year crop, pasture and forest land-use managements. Global Change Biol., 10: 65-78.

McKissock I, Walker EL, Gilkes RJ and Carter DJ 2000 The influence of clay type on reduction of water repellency by applied clays: a review of some West Australian work. J. Hydrol., 231232: 323-332

McKissock I, Gilkes RJ and Walker EL 2002 The reduction of water repellency by added clay is influenced by clay and soil properties. Applied Clay Science, 20: 225-241.

Miyamoto S, Letey J and Osborn J 1972 Water vapor adsorption by water-repellent soils at equilibrium. Soil Sci., 114: 180-184.

Wallis MG, Scotter DR and Horne DJ 1991 An evaluation of the intrinsic sorptivity water repellency index on a range of New Zealand soils. Aust. J. Soil Res., 29: 353-362. 